\title{
Influence of the Anomalous Patterns of the Mascarene and Australian Highs on Precipitation during the Prerainy Season in South China
}

\author{
Xue Han, ${ }^{1}$ Fengying Wei, ${ }^{2}$ and Xingrong Chen ${ }^{1}$ \\ ${ }^{1}$ National Marine Environmental Forecasting Center, Beijing 100081, China \\ ${ }^{2}$ State Key Laboratory of Severe Weather, Chinese Academy of Meteorological Sciences, Beijing 100081, China \\ Correspondence should be addressed to Xue Han; han_xuel129@hotmail.com
}

Received 15 November 2016; Revised 18 March 2017; Accepted 5 April 2017; Published 30 April 2017

Academic Editor: Marina Baldi

Copyright (C) 2017 Xue Han et al. This is an open access article distributed under the Creative Commons Attribution License, which permits unrestricted use, distribution, and reproduction in any medium, provided the original work is properly cited.

\begin{abstract}
The authors investigate the features of precipitation during the prerainy season in South China (PSCPRS) and the atmospheric circulation in the Southern Hemisphere (SH), which is expected to influence the PSCPRS significantly. The Morlet wavelet method revealed that the PSCPRS has significant interannual variability, especially in its quasi-biennial oscillation. The PSCPRS exhibits a significant monsoonal precipitation pattern. Using singular value decomposition (SVD) and composite analysis, the anomalous characteristics of SH atmospheric circulations and their impacts on the PSCPRS are studied. The results reveal that eastward movements or extensions of the Mascarene high (MH) and Australian high ( $\mathrm{AH})$, which have quasi-baroclinic geopotential height structures in the lower and middle troposphere, are the most significant factors affecting the PSCPRS. Their impacts on the PSCPRS anomalies are further studied using the index east of the MH (IEMH) and index east of the AH (IEAH). The IEMH and IEAH have notable significant positive correlations with the PSCPRS. When either the IEMH or IEAH is stronger (weaker), more (less) rainfall occurs during the prerainy season in South China.
\end{abstract}

\section{Introduction}

Heavy rainstorms and droughts, which are occurring at an increasing frequency in South China, seriously affect regional economic development and the livelihood of the local population. The rainy season in South China extends from April to September. Some parts of South China receive up to $40 \%-50 \%$ of their total annual rainfall in just three months (i.e., from April to June), which is called the prerainy season. Since South China is located in the subtropics and tropics, the atmospheric circulation system in the Southern Hemisphere $(\mathrm{SH})$ is one of the most important factors affecting the climate anomalies in South China. How the precipitation in South China during the prerainy season (PSCPRS) can be affected by the atmospheric circulations in the $\mathrm{SH}$ is an important component of understanding the overall relationship between the $\mathrm{SH}$ circulation system and climate anomalies in East Asia. A number of recent studies have suggested that the Antarctic Oscillation (AAO), which is a principal mode of the large-scale circulation in the $\mathrm{SH}$, is probably the most important pattern of climate variability in the middle and high latitudes of the $\mathrm{SH}$. The climate impacts of the AAO are not limited to the $\mathrm{SH}[1-4]$ but are also closely related to some anomalous climate events in the Northern Hemisphere (NH) [5, 6], especially the monsoon system [7-9] and precipitation [10-13]. An anomalous AAO can change the location and intensity of summer circulation systems, which are important to the rainfall in eastern China [10, 14-17]. Zheng and $\mathrm{Li}$ [18] found that the boreal winter AAO is significantly correlated with the spring precipitation over South China. Xue [19] found that the AAO is highly related to the interannual variability of the East Asia summer monsoon (EASM). Although the above links between $\mathrm{AAO}$ and regional climates in the $\mathrm{NH}$ are statistically significant, a crucial issue is how the climate variability in the $\mathrm{NH}$ can be affected by atmospheric circulation anomalies in the SH. For instance, Tomas and Webster [20] found that interhemispheric wave propagation occurs through the equatorial upper-tropospheric mean 
westerlies in the eastern Pacific. Nan et al. [21] revealed that changes in the Indian Ocean circulation could play a "bridge" role in transmitting the influence of the AAO into the $\mathrm{NH}$.

Moreover, studies of the spatial distribution of the regional circulation in the $\mathrm{SH}$ indicated that atmospheric circulations in the mid-latitudes of the $\mathrm{SH}$ are associated with regional climate anomalies [22-27]. Cold air activities in the mid-latitudes of the SH can affect the onset and evolution of EASM. From the perspective of regional circulation systems, subtropical highs in SH, especially the Australian high (AH) and Mascarene high $(\mathrm{MH})$, have particularly significant impacts on EASM [28-31]. Tao et al. [32] showed that when a meridional circulation prevails over the subtropics and tropics in East Asia, a meridional circulation also occurs in the SH (especially in Australia) and that a mass transport from the $\mathrm{SH}$ to the $\mathrm{NH}$ is observed. Thus, anomalies of the $\mathrm{AH}$ may trigger the anomalous onset of the EASM. Wang and $\mathrm{Li}$ [33] and Teng et al. [34] found that, as a member of the Asian-Australian monsoon circulation system, the interannual variation of AH may be strongly connected to the Asian monsoon circulation, especially the cross-equatorial flows (CEFs) near $100^{\circ}-160^{\circ} \mathrm{E}$, thereby further affecting the climatic characteristics of China. In studies focused on the SH circulation system, the MH was shown to not only have key effects the on Indian monsoon circulation but also influence the Asian monsoon circulation to some extent. Xue et al. [35] and Xue and He [36] noted that the presence of the $\mathrm{AH}$ and $\mathrm{MH}$ in April can trigger the onset of the South China Sea summer monsoon (SCSSM) and EASM through CEFs. Numerical model experiments performed by Yang and Huang [37] and Xue et al. [30] confirmed the impact of the $\mathrm{MH}$ on the EASM.

Previous studies have also investigated the impacts of the $\mathrm{AH}$ and $\mathrm{MH}$ on the summer rainfall in various regions of eastern China. Xue et al. [35] suggested that the intensity of the $\mathrm{MH}$ has a significant positive correlation with the summer rainfall over the north of the Yangtze River and that an intense $\mathrm{AH}$ promotes summer rainfall in South China. Tao and Sun [38] reported a substantially positive correlation between the spring $\mathrm{MH}$ and the Meiyu precipitation in the Yangtze-Huaihe basin. Shi and Zhu [39] argued that summer precipitation anomalies in South China are significantly triggered by $\mathrm{MH}$ variability. However, few discussions have addressed the effects of the $\mathrm{SH}$ atmospheric circulation on the PSCPRS. Indeed, knowledge of the variation characteristics of the PSCPRS and its responses to circulation systems in the $\mathrm{SH}$ remains inadequate.

In this study, we aimed to identify the crucial factors in the SH that significantly affect PSCPRS and analyze the possible underlying physical mechanisms. The paper is organized as follows. A brief description of the datasets is given in Section 2. Section 3 introduces the main characteristics of the PSCPRS. Section 4 presents the characteristics of the atmospheric circulation in the SH associated with the PSCPRS anomalies. This is followed by an investigation of the possible physical mechanisms, which is based on composite analyses of atmospheric circulations in the SH. Finally, Section 5 contains a summary and a discussion of the main results obtained in this study.

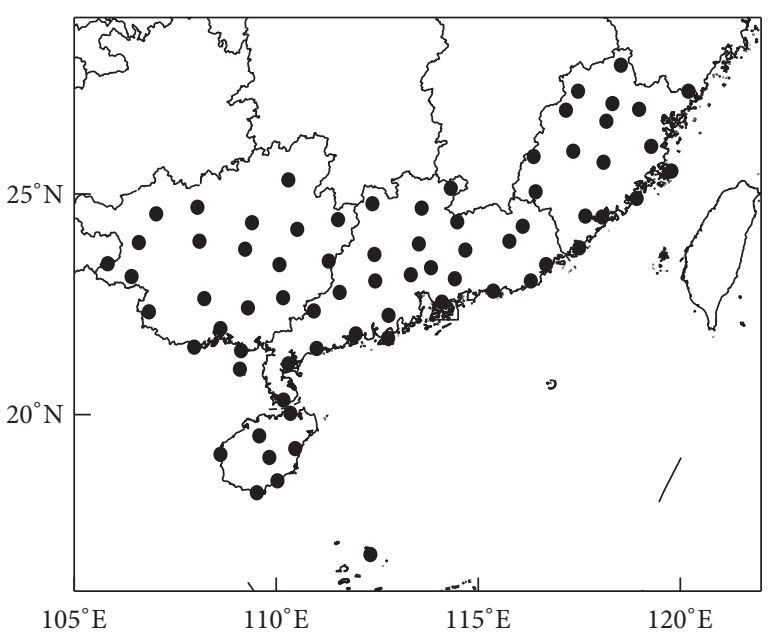

FIgURE 1: The 71 rainfall stations in South China.

\section{Data and Methods}

The daily precipitation datasets of 71 stations (Figure 1) in four provinces (Fujian, Guangdong, Guangxi, and Hainan) in South China were obtained from the National Meteorological Information Center. The monthly geopotential height (GH), sea-level pressure (SLP), $850 \mathrm{hPa}$ meridional wind, and specific humidity datasets were derived from the National Centers for Environmental Prediction/National Center for Atmospheric Research (NCEP/NCAR). The sea surface temperature (SST) data were obtained from the National Oceanic and Atmospheric Administration (NOAA) with a resolution of $2.0^{\circ} \times 2.0^{\circ}$. All of the above datasets span a $48 \mathrm{yr}$ period from 1960 to 2008. In both datasets, the monthly data were converted into anomalies by subtracting the $30 \mathrm{yr}$ climatology of 1971-2000. The prerainy season is defined as the 3-month average from April to June.

Composite analysis is a common method of observing the responses associated with certain climate conditions by averaging the data over the considered years. Morlet wavelet analysis was used to detect the variation periods of the PSCPRS. The singular value decomposition (SVD) analysis method was employed to illustrate the potential covariability between PSCPRS and SLP anomalies in the SH. Student's $t$ test and $u$-test were used to assess the statistical significance of the results obtained from the composite and correlation analyses.

\section{Characteristics of the PSCPRS}

The average rainfall values at the 71 stations, from April to June, were standardized to show the interannual variability of the PSCPRS during 1960-2008 (Figure 2(a)). Severe floods and droughts occurred frequently from the early 1960s to the mid-1970s and after the 1990s. We find 9 flood years (1965, $1973,1975,1993,1998,2001,2005,2006$, and 2008) with standardized values greater than 1.0 and 7 drought years (1963, $1967,1985,1991,1995,2002$, and 2004) with standardized values less than -1.0. The composite analyses of the PSCPRS in flood years (Figure 2(b)) and in drought years (Figure 2(c)) 


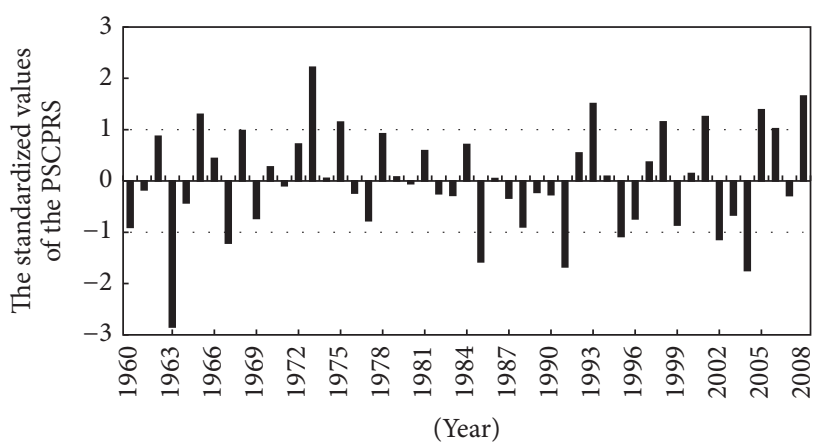

(a)

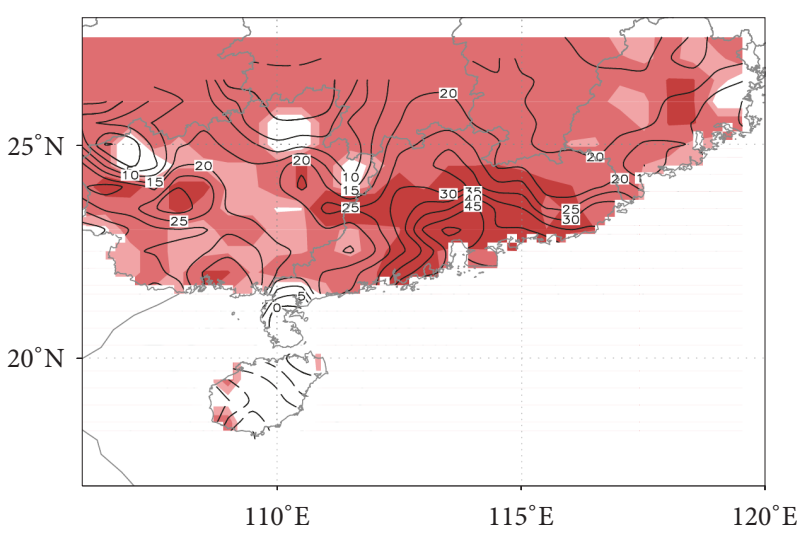

(b)

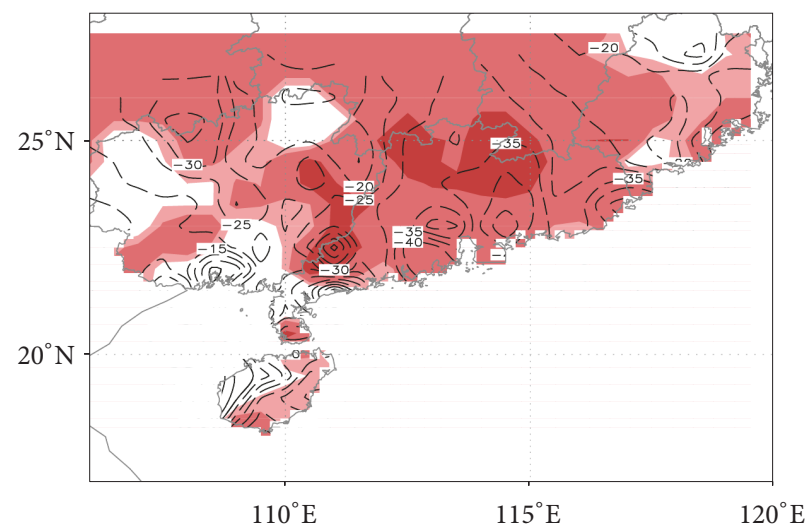

(c)

FIGURE 2: (a) Standardized values of the PSCPRS. Composite distributions of the PSCPRS in flood years (b) and drought years (c). Significant values exceeding the $90 \%, 95 \%$, and $99 \%$ confidence levels ( $t$-test) are shaded.

are shown. The maxima of the precipitation anomalies are located in the middle of the Guangdong province and in the coastal areas of South China. Morlet wavelet method was applied to identify the multiple timescales of the variability of the PSCPRS. Figure 3 presents both the wavelet transforms (Figure 3(a)) and the wavelet variances (Figure 3(b)). The alternations between positive and negative values centered around multiple periods exhibit significant interannual variability (Figure 3(a)). Multiple interannual periods can be found: an obvious $2 \mathrm{yr}$ to $4 \mathrm{yr}$ oscillation period before the mid-1960s, a quasi-biennial oscillation (QBO) during the late 1960s and 1970s, a 3 yr oscillation in the 1980s, and a QBO and 5-year oscillation since the 1990s. Moreover, a 7year period of oscillation, which is on the scale of El Niño Southern Oscillation (ENSO) variability, can be seen from the 1960s to the 1980s. Wavelet analysis indicates that the PSCPRS exhibits multiple timescales of oscillation periods, and its characteristics agree with previous results [40]. Furthermore, the $2 \mathrm{yr}$ period, which has the highest frequency wavelet variance (Figure 3(b)), indicates significant QBO variability of the PSCPRS. The significant QBO fluctuation in the PSCPRS indicates that the PSCPRS exhibits significant monsoonal rainfall characteristics that are affected by the atmospheric circulation in the SH $[33,34]$. Therefore, the anomalous variations of the atmospheric circulations in the $\mathrm{SH}$ and their impacts on the PSCPRS are analyzed.

\section{Relationship between Atmospheric Circulations in the SH and the PSCPRS}

4.1. SVD Analysis of the PSCPRS and SLP of the SH. The atmospheric circulation systems in the $\mathrm{SH}$ have received increased attention due to their influences on the EASM, especially the $\mathrm{MH}\left(25^{\circ}-35^{\circ} \mathrm{S}, 40^{\circ}-90^{\circ} \mathrm{E}\right)$ and the $\mathrm{AH}\left(25^{\circ}-35^{\circ} \mathrm{S}, 120^{\circ}-150^{\circ} \mathrm{E}\right)$ [31, 35]. To identify possible links between atmospheric circulation in the SH and PSCPRS variations, the SVD method was applied to the cross-covariance matrix between the SLP $\left(60^{\circ} \mathrm{S}-0,60^{\circ} \mathrm{E}-180^{\circ}\right)$ and PSCPRS. The first SVD mode accounts for $65.58 \%$ of the total covariance, and the correlation coefficient between the expansion coefficients for the PSCPRS and SLP is 0.438, which passes the $99 \%$ confidence level of the $t$-test. Figure 4 shows components of the first SVD modes for the coupled fields. The PSCPRS mode has a monopole structure. Positive coefficients that are above the $99 \%$ confidence level are seen over most of South China, as shown in Figure 4(a); thus, the PSCPRS is highly related 


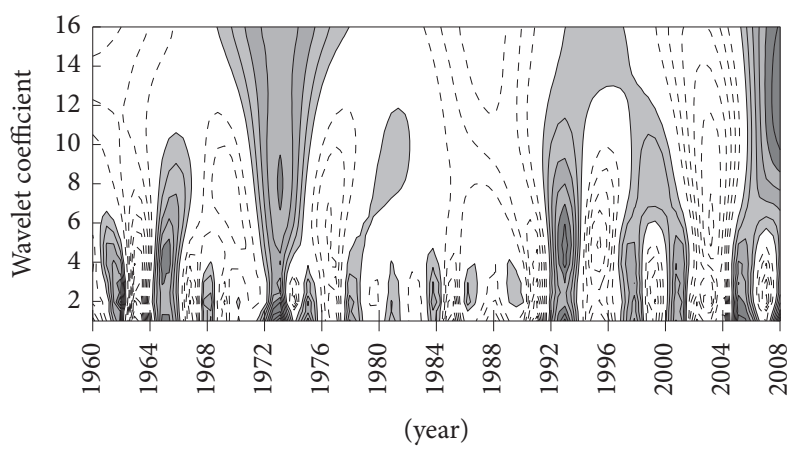

(a)

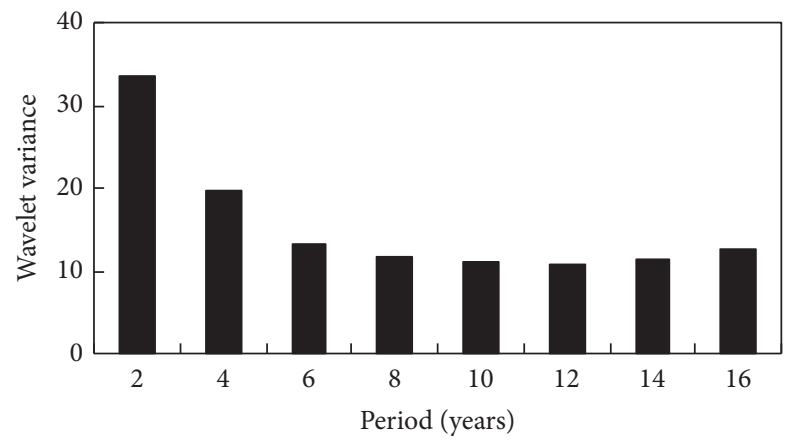

(b)

FIGURE 3: Wavelet transform (a) and wavelet variance (b) of the PSCPRS.

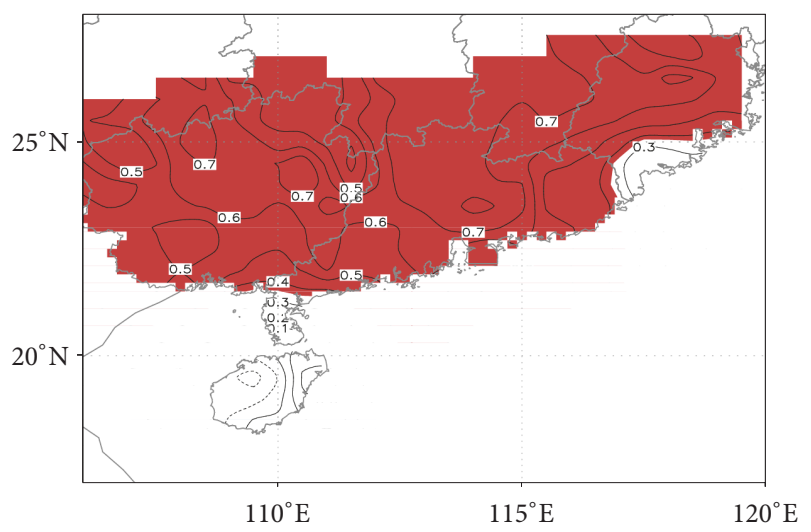

(a)

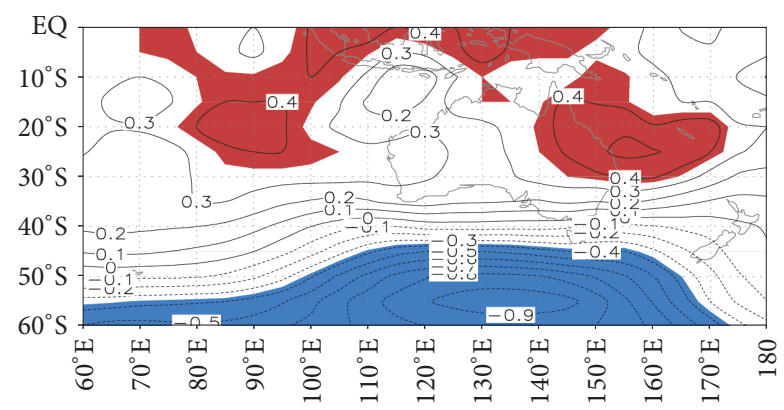

(b)

FIGURE 4: Correlations of the first SVD mode of the PSCPRS (a) and SLP (b). Significant values exceeding the 99\% confidence level $(t$-test) are shaded. to the SLP. The first SLP mode displays an out-of-phase relationship between the SLP anomalies north and south of $50^{\circ} \mathrm{S}$ (Figure $4(\mathrm{~b})$ ). The significant SLP anomaly centers, which exceed the $99 \%$ confidence level, are located in the eastern mid-latitudes of the South Indian Ocean $\left(10^{\circ}-25^{\circ} \mathrm{S}\right.$, $\left.80^{\circ}-100^{\circ} \mathrm{E}\right)$ and east of Australia $\left(15^{\circ}-30^{\circ} \mathrm{S}, 140^{\circ}-170^{\circ} \mathrm{E}\right)$. The SLP pattern is somewhat similar to the AAO mode, which is characterized by pressure anomalies of one sign centered in the Antarctic and anomalies of the opposite sign centered at approximately $40^{\circ}-50^{\circ} \mathrm{S}$. The SVD analysis indicates that the positive SLP anomalies in the eastern mid-latitudes of the South Indian Ocean and east of Australia are significantly associated with a positive PSCPRS.

4.2. Composite Analysis of the SLP Associated with PSCPRS Anomalies. To illustrate the behavior of the first SVD mode of variability in terms of atmospheric configurations, Figure 5 presents composites distributions of the SLP anomalies corresponding to the flood and drought years of the PSCPRS. The results show that the SLP anomalies of flood and drought years exhibit an opposite pattern for $80^{\circ}-170^{\circ} \mathrm{E}$. In flood years (Figure 5(a)), notable positive SLP anomalies dominate the ocean east of the Philippines. In the $\mathrm{SH}$, our focus in this study, positive SLP anomalies are located in the mid-latitudes of the $\mathrm{SH}$, the eastern mid-latitude regions of the South Indian Ocean and east of Australia $\left(25^{\circ}-40^{\circ} \mathrm{S}\right.$, $90^{\circ}-180^{\circ} \mathrm{E}$ ), whereas negative SLP anomalies dominate most of the high latitudes in the SH. The shading indicates that significant positive SLP anomalies are located in the ocean east of the Philippines and the east of Australia in flood years. The characteristic features of SLP anomalies in drought years (Figure 5(b)) exhibit a pattern that is largely opposite that of flood years. Negative SLP anomalies are found in the eastern mid-latitudes of the South Indian Ocean and east of Australia, positive SLP anomalies are seen in the south of Australia, and the ocean east of the Philippines becomes a center of negative SLP anomalies. The shading indicates that the significant negative SLP anomalies are located in the ocean east of the Philippines and over the eastern mid-latitudes of the South Indian Ocean in drought years. The differences values ( $D$-values) between the SLP anomalies of flood and drought years are computed to further identify characteristic features of the SLP anomalies (Figure 5(c)). The shaded areas, which indicate $D$-values that were significant at the $95 \%$ confidence level ( $t$-test), are key areas that impact the PSCPRS anomalies. Significant positive centers are found over the ocean east of the Philippines. The relationship between the Asia summer monsoon and the structure of the Asian subtropical anticyclone has been widely discussed [41-43]. In the SH, two significant positive centers are located over the eastern mid-latitudes of the Southern Indian Ocean $\left(25^{\circ}-40^{\circ} \mathrm{S}, 85^{\circ}-110^{\circ} \mathrm{E}\right)$ and east of Australia $\left(25^{\circ}-35^{\circ} \mathrm{S}, 155^{\circ}-165^{\circ} \mathrm{E}\right)$, whereas a significant negative center occurs in the south of Australia. The above analyses indicate that the crucial areas of the atmospheric anomalies that influence the PSCPRS significantly are not consistent with the traditional definitions of the $\mathrm{MH}\left(25^{\circ}-35^{\circ} \mathrm{S}, 40^{\circ}-90^{\circ} \mathrm{E}\right)$ and $\mathrm{AH}\left(25^{\circ}-35^{\circ} \mathrm{S}, 120^{\circ}-150^{\circ} \mathrm{E}\right)[31,35]$; instead, they are located to the east of the $\mathrm{MH}$ and the $\mathrm{AH}$ regions. Therefore, in the $\mathrm{SH}$, 


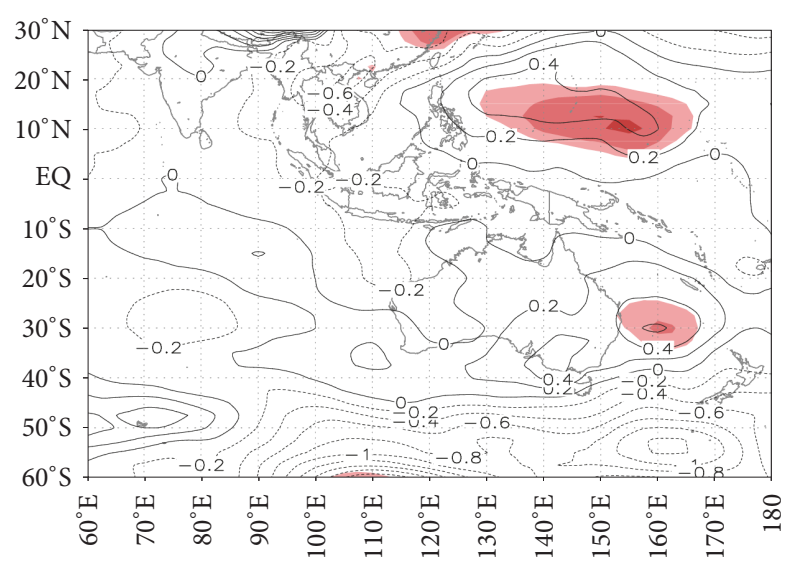

(a)

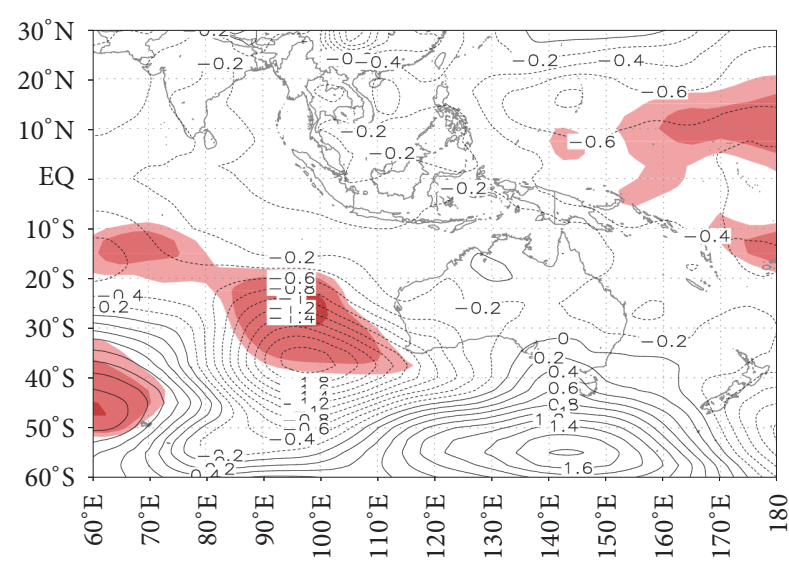

(b)

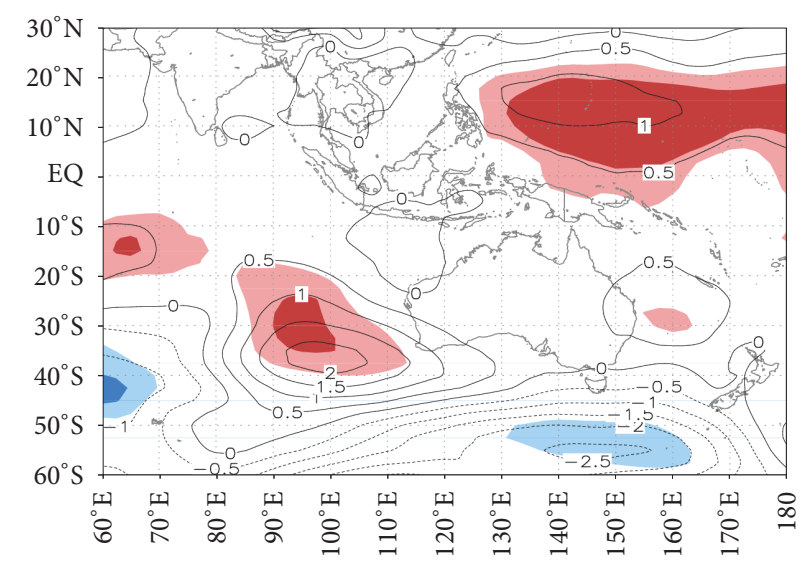

(c)

Figure 5: Composite distributions of the SLP anomalies in flood years (a) and drought years (b). Panel (c) shows the $t$-test results of the $D$-values between the flood and drought years. Significant values exceeding the $90 \%, 95 \%$, and $99 \%$ confidence levels $(t$-test) are shaded.

anomalous patterns of the $\mathrm{MH}$ and $\mathrm{AH}$ (moving or extending eastward) may be more significantly associated with PSCPRS anomalies.

\subsection{Composite Analysis of the GH Associated with the PSCPRS} Anomalies. We further examined the vertical structure of the geopotential high fields associated with the PSCPRS anomalies. The GH anomalies in the flood and drought years are investigated using a composite analysis for the period of 1960-2008, similar to the analysis of the SLP anomalies. The results show that the GH anomalies of flood and drought years exhibit similar patterns from $1000 \mathrm{hPa}$ to $200 \mathrm{hPa}$. The composite analyses of the $\mathrm{GH}$ anomalies at $850 \mathrm{hPa}$ and $500 \mathrm{hPa}$ are displayed in Figure 6. In flood years, positive $\mathrm{GH}$ anomalies at $850 \mathrm{hPa}$ (Figure 6(a1)) and $500 \mathrm{hPa}$ (Figure 6(a2)) are found in the ocean east of the Philippines and in the mid-latitudes of the SH (centered on Australia), whereas negative GH anomalies are found in the high latitudes of the SH. In drought years, notable negative $\mathrm{GH}$ anomalies at both $850 \mathrm{hPa}$ (Figure 6(bl)) and $500 \mathrm{hPa}$ (Figure 6(b2)) are located in the eastern mid-latitude region of the South Indian Ocean and east of Australia in the SH, whereas positive $\mathrm{GH}$ anomalies are found in the high-latitude of the SH. The GH anomalies over Australia do not show opposite distributions in flood and drought years; however, the GH intensity over Australia in drought years is weaker than that observed in flood years. Significant positive and negative GH anomalies, which exceed the $95 \%$ confidence level, occur to the east of Australia and in the eastern midlatitudes of the South Indian Ocean. The results further substantiate the anomalous patterns of the $\mathrm{MH}$ and $\mathrm{AH}$ (moving or extending eastward), which may be more significantly associated with the PSCPRS anomalies. The $D$-values of the $\mathrm{GH}$ between flood and drought years at $850 \mathrm{hPa}$ are displayed in Figure 6(cl). Significant areas influencing the PSCPRS anomalies (i.e., those exceeding the $95 \%$ confidence level $[t$ test]) are located over the ocean east of the Philippines, the eastern mid-latitudes of the South Indian Ocean, and east of Australia. Figure 6(c2) shows the distribution of the crucial areas at $500 \mathrm{hPa}$ that were significant at the $95 \%$ confidence level; this pattern is similar to that observed at $850 \mathrm{hPa}$. However, the significant area in the eastern mid-latitudes of the South Indian Ocean at $500 \mathrm{hPa}$ is farther west than that at $850 \mathrm{hPa}$, and no significant area of influence is found east of Australia at $500 \mathrm{hPa}$.

To better illustrate the GH anomalies associated with the PSCPRS anomalies, a longitude-altitude section along $30^{\circ} \mathrm{S}$ of the $t$-test coefficients for the $D$-values between flood and 


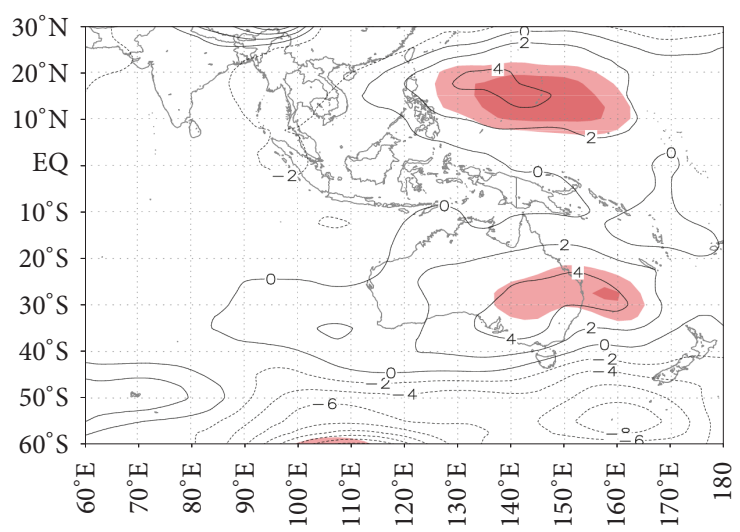

(a1)

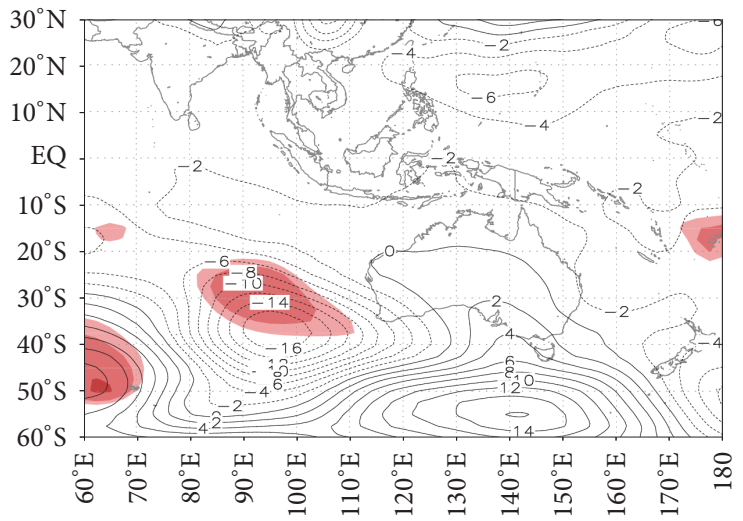

(b1)

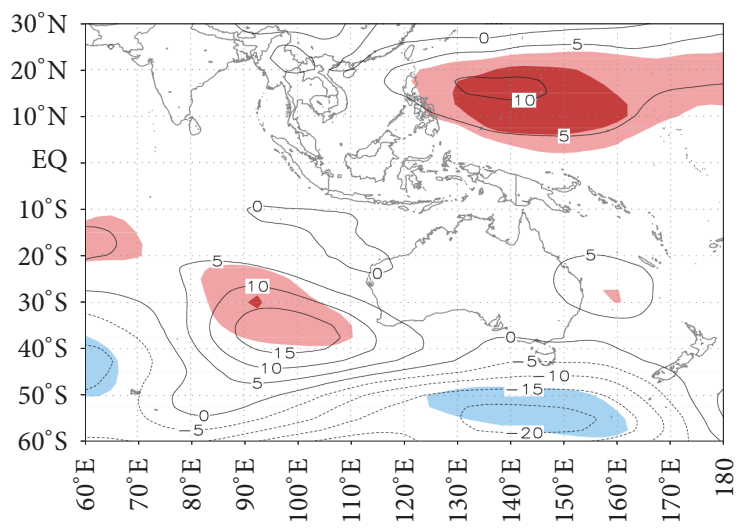

$(\mathrm{c} 1)$

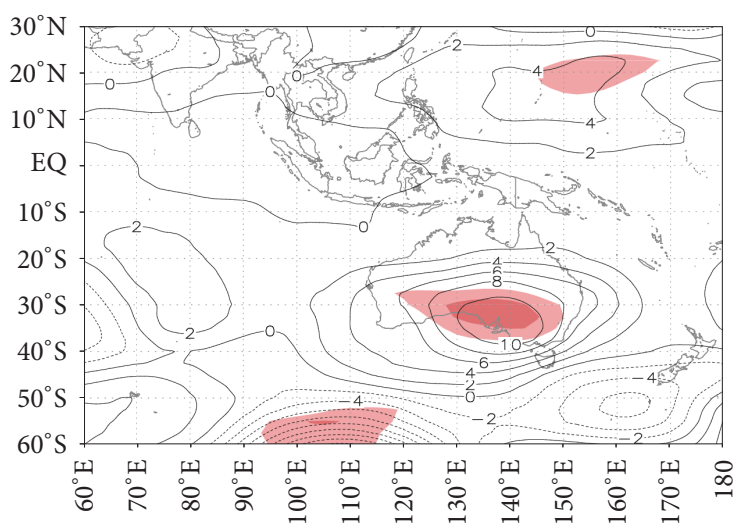

(a2)

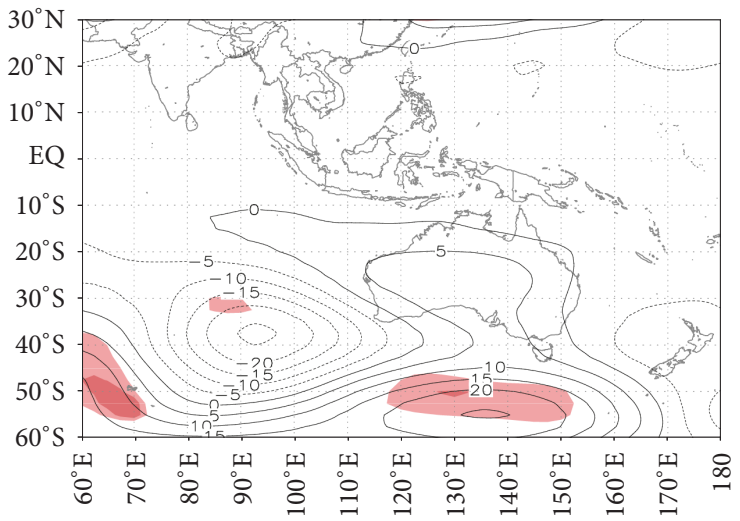

(b2)

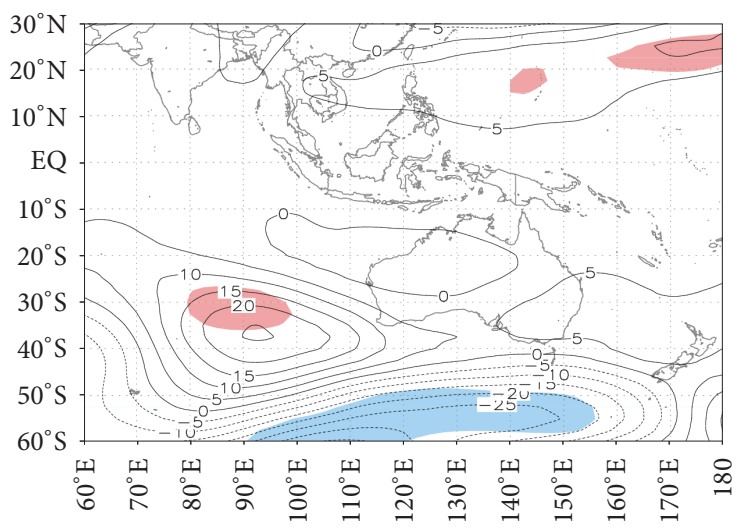

(c2)

FIGURE 6: Composite distributions of the GH anomalies in the prerainy season in South China. The panels on the left correspond to the values at $850 \mathrm{hPa}$ in flood years (al) and drought years (b1) and the $t$-test results of the $D$-values between flood and drought years (c1). The corresponding panels on the right show the same results, but at $500 \mathrm{hPa}$. Significant values exceeding the $90 \%$, $95 \%$, and $99 \%$ confidence levels $(t$-test) are shaded.

drought years is shown in Figure 7. The shaded areas indicate that the $D$-values are significant at the $95 \%$ confidence level $(t$-test). Figure 7 presents the vertical spatial structure of atmospheric circulation in the mid-latitudes of the $\mathrm{SH}$ that impacts the PSCPRS anomalies. Significant areas are located at approximately $90^{\circ} \mathrm{E}-100^{\circ} \mathrm{E}$ and $160^{\circ} \mathrm{E}$. Remarkably, in the eastern mid-latitudes of the South Indian Ocean (east of the $\mathrm{MH}$ ), a significant quasi-baroclinic structure slopes gently to the west from $1000 \mathrm{hPa}$ to $200 \mathrm{hPa}$. However, the significant area in the east of Australia (east of the $\mathrm{AH}$ ) only appears from $1000 \mathrm{hPa}$ to $850 \mathrm{hPa}$. The high-pressure system in the east of the $\mathrm{MH}$ is much deeper than that in the east of the $\mathrm{AH}$.

From the above discussion, we may conclude that the position and strength modifications of the subtropical highs in the $\mathrm{SH}$, including the eastward movements or extensions of the $\mathrm{MH}$ and $\mathrm{AH}$, may strongly impact the PSCPRS anomalies. 


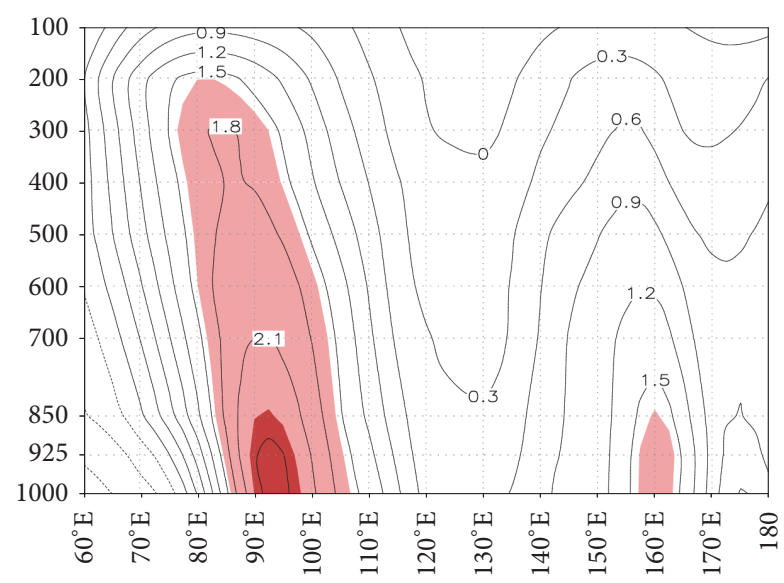

FIgure 7: The $t$-test of $D$-values for the $\mathrm{GH}$ anomalies along $30^{\circ} \mathrm{S}$ between flood and drought years. Significant values exceeding the $90 \%, 95 \%$, and $99 \%$ confidence levels ( $t$-test) are shaded.

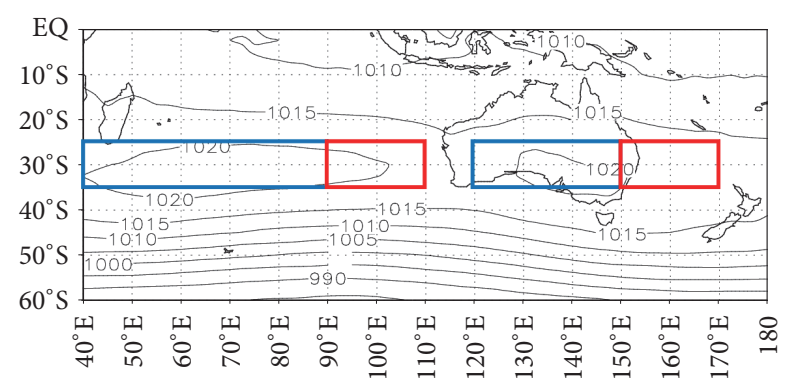

FIGURE 8: The $30 \mathrm{yr}$ climatology SLP in the prerainy season from 1971 to 2000 (contour). The blue rectangular boxes represent the $\mathrm{MH}\left(25^{\circ}-35^{\circ} \mathrm{S}, 40^{\circ}-90^{\circ} \mathrm{E}\right)$ and $\mathrm{AH}\left(25^{\circ}-35^{\circ} \mathrm{S}, 120^{\circ}-150^{\circ} \mathrm{E}\right)$ regions; the red rectangular boxes represent the IEMH $\left(25^{\circ}-35^{\circ} \mathrm{S}, 90^{\circ}-110^{\circ} \mathrm{E}\right)$ and IEAH $\left(25^{\circ}-35^{\circ} \mathrm{S}, 150^{\circ}-170^{\circ} \mathrm{E}\right)$ regions.

Recently, variations in the location of the MH center and its influences on the rainfall over equatorial eastern Africa have been investigated [22]. Moreover, the study of Ohishi et al. [23], which discussed the zonal movement of the Mascarene high in austral summer, indicated that the SLP variations in the eastern part of the South Indian Ocean (ESIO) $\left(30^{\circ}-35^{\circ} \mathrm{S}\right.$, $\left.105^{\circ}-115^{\circ} \mathrm{E}\right)$ and the western part of the South Indian Ocean (WSIO) $\left(30^{\circ}-35^{\circ} \mathrm{S}, 60^{\circ}-70^{\circ} \mathrm{E}\right)$ regions are associated with the $\mathrm{MH}$ longitudinal movement. Therefore, to better discuss the influences of the eastward movements or extensions of the $\mathrm{MH}$ and $\mathrm{AH}$ on the PSCPRS anomalies, two indices were defined in this study (Figure 8). Referring to the traditional definition of the $\mathrm{MH}$ and $\mathrm{AH}$, an index called the index for the east of the MH (IEMH), which is defined by standardizing the average SLP over $25^{\circ}-35^{\circ} \mathrm{S}, 90^{\circ}-110^{\circ} \mathrm{E}$. Similarly, the index for the east of the $\mathrm{AH}$ (IEAH) is defined by standardizing the average SLP over $25^{\circ}-35^{\circ} \mathrm{S}$ and $150^{\circ}-170^{\circ} \mathrm{E}$. These two indices represent the eastward movements or extensions of the $\mathrm{MH}$ and $\mathrm{AH}$, respectively. The correlation coefficient between the IEMH and the PSCPRS is 0.33 , which passes the 95\% confidence level ( $t$-test), and the correlation coefficient between the IEAH and the PSCPRS is 0.25 , which passes the
$90 \%$ confidence level ( $t$-test). In contrast, the PSCPRS shows a negligible correlation with the traditional definitions of the $\mathrm{MH}$ and $\mathrm{AH}$. The results of the correlation analysis indicate that IEMH and IEAH are more significantly correlated with the PSCPRS than the $\mathrm{MH}$ and $\mathrm{AH}$. When either IEMH or IEAH is stronger (weaker), there is more (less) rainfall during the prerainy season in South China. However, these results do not indicate how the eastward movements or extensions of the $\mathrm{MH}$ and $\mathrm{AH}$ influence the PSCPRS anomalies.

4.4. Possible Effects of the High-Pressure Systems in the SH on PSCPRS Anomalies. The above analysis revealed that the eastward movements or extensions of the $\mathrm{MH}$ and $\mathrm{AH}$ have significant effects on the PSCPRS anomalies. Considering the abundant water vapor in the $\mathrm{SH}$ that moves through the CEF and the SCSSM into the South China region during the prerainy season, in this section, we explore the possible impact of atmospheric circulation anomalies in the $\mathrm{SH}$ on the CEFs and water vapor transport affecting the PSCPRS anomalies.

4.4.1. Possible Effects on $850 \mathrm{hPa}$ Meridional Wind and Water Vapor Transport. We first calculate the $D$-values for the meridional wind anomalies at $850 \mathrm{hPa}$ (Figure 9(a)) and the total meridional water vapor flux from $1000 \mathrm{hPa}$ to $300 \mathrm{hPa}$ (Figure 9(b)) between flood and drought years. Positive (negative) $D$-values indicate that the southerly winds and water vapor flux for the flood (drought) years are stronger than during the drought (flood) years, while the shaded areas correspond to $D$-values that are significant at the $95 \%$ confidence level ( $t$-test). The significant $D$-values for the meridional wind anomalies at $850 \mathrm{hPa}$ and the total meridional water vapor flux show similar distributions. Positive centers located at $25^{\circ}-40^{\circ} \mathrm{S}, 95^{\circ}-115^{\circ} \mathrm{E} ; 0^{\circ}-10^{\circ} \mathrm{S}, 75^{\circ}-80^{\circ} \mathrm{E}$; and $5^{\circ}-15^{\circ} \mathrm{N}, 65^{\circ}-75^{\circ} \mathrm{E}$ are distributed like a band from the southeast to the northwest. Meanwhile, positive centers are located over the eastern Australia and the SCS. This distribution pattern means that, in flood years, stronger southerly winds with abundant water vapor appear from the eastern mid-latitude region of the South Indian Ocean to the eastern Arabia Sea, eastern Australia, and the SCS. Negative centers presenting stronger northerly winds in flood years are located in the middle of the South Indian Ocean $\left(25^{\circ}-45^{\circ} \mathrm{S}, 70^{\circ}-90^{\circ} \mathrm{E}\right)$, eastern Australia, and the ocean east of the Philippines. Three pairs of positive and negative centers demonstrate three strong anticyclone centers around the eastern mid-latitude region of the South Indian Ocean, eastern Australia, and the Philippines, in agreement with the analysis of $\mathrm{GH}$ anomalies. In summary, the eastward movements or extensions of the $\mathrm{MH}$ and $\mathrm{AH}$ represented by IEMH and IEAH are crucial factors for PSCPRS anomalies.

4.4.2. Possible Dynamics. As proposed in previous studies, the anomalous CEFs are closely related to the $\mathrm{GH}$ anomalies in the $\mathrm{SH}$ and have important impacts on the East Asian monsoon onset and climate variations in East China [30, 44]. We further discussed the respective influences of the IEMH and IEAH on the lower atmospheric circulation based on correlation analysis. Figure 10(a) shows the correlation coefficients 


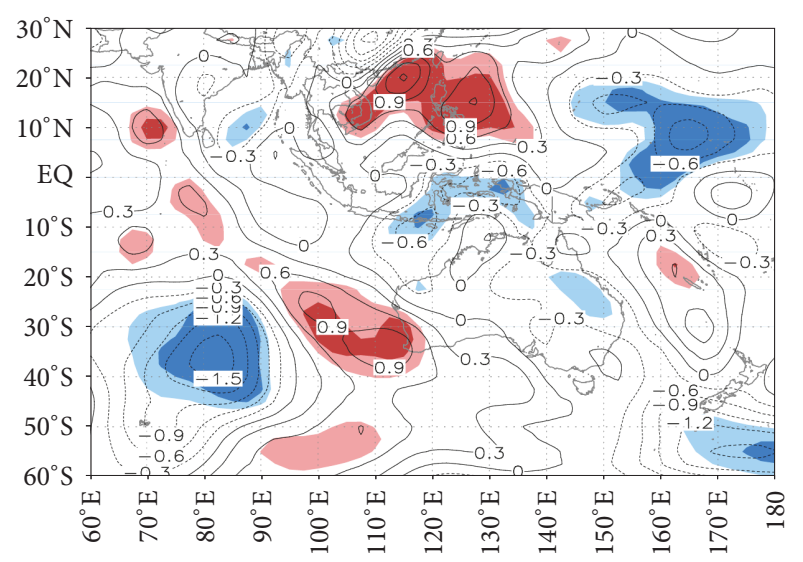

(a)

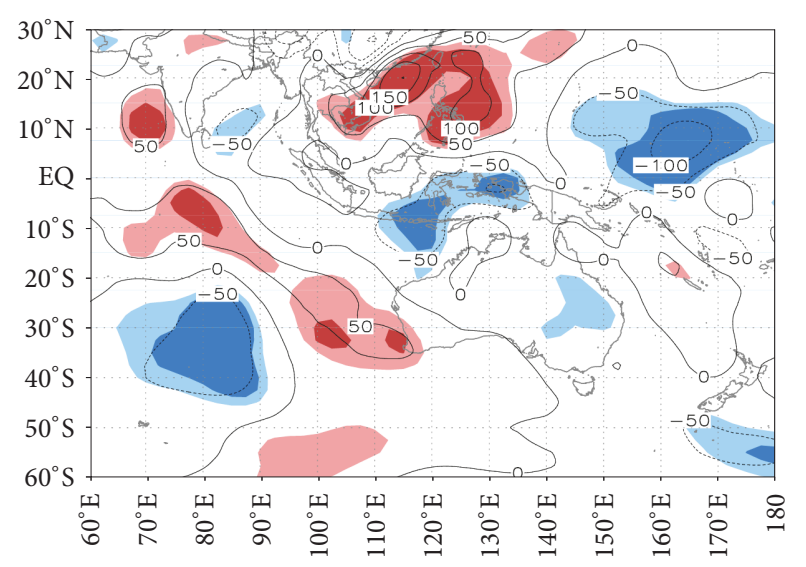

(b)

FIGURE 9: The $t$-test of $D$-values of the meridional wind anomalies at $850 \mathrm{hPa}$ (a) and the total meridional water vapor flux from $1000 \mathrm{hPa}$ to $300 \mathrm{hPa}(\mathrm{b})$ between flood and drought years. Significant values exceeding the $90 \%, 95 \%$, and $99 \%$ confidence levels ( $t$-test) are shaded.

between the $850 \mathrm{hPa}$ meridional winds and IEAH. Positive shaded areas, which are significant at the 95\% confidence level ( $t$-test), indicate that when IEAH is strong the prevailing flow is southerly winds at $850 \mathrm{hPa}$. Southerly winds intensify over eastern Australia from the mid-high latitudes of the $\mathrm{SH}$ to the tropical regions of the $\mathrm{NH}$, crossing the equator at $140^{\circ}-150^{\circ} \mathrm{E}, 120^{\circ}-130^{\circ} \mathrm{E}$, and $100^{\circ}-110^{\circ} \mathrm{E}$. Thus, when the IEAH is stronger, the CEFs near $140^{\circ}-150^{\circ} \mathrm{E}, 120^{\circ}-130^{\circ} \mathrm{E}$, and $100^{\circ}-110^{\circ} \mathrm{E}$ strengthen, whereas the $\mathrm{CEF}$ at $120^{\circ}-130^{\circ} \mathrm{E}$ could move as far north as $15^{\circ} \mathrm{N}$. In this atmospheric circulation pattern, the abundant water vapor stretching from the South Pacific, along the eastern edge of the anticyclone located in east of Australia, through CEFs, into the NH, enhances the rainfall in South China. The correlation coefficients between the surface wind divergence and velocity potential over the IEAH are shown in Figures 10(b) and 10(c), respectively. Negative shaded areas, which are significant at the $95 \%$ confidence level ( $t$-test), indicate that when the IEAH is strong surface convergence is enhanced. Significant negative areas, which indicate horizontal convergence, are located over the eastern Australia and the South China (Figure 10(b)). When the IEAH is strong, the horizontal convergence center can trigger ascending motion and favor the rainfall over the South China. The significant horizontal wind convergence centers which are located over the South China and the northern SCS favor ascending motion and regional rainfall (Figure 10(c)). The correlation coefficients between the $850 \mathrm{hPa}$ meridional winds and the IEMH are displayed in Figure 10(d), and significant horizontal convergence centers can also be found over the South China and the northern SCS (Figures 10(e) and $10(\mathrm{f})$ ). Southerly winds intensify over the eastern region of the South Indian Ocean. However, the stronger CEFs are not located to the east of $100^{\circ} \mathrm{E}$ but at $50^{\circ}-60^{\circ} \mathrm{E}$, near Somali. This feature indicates that, because of the stronger anticyclone located in the eastern part of the South Indian Ocean, enhanced southerly winds along the edge of the anticyclone that cross the equator at $50^{\circ}-60^{\circ} \mathrm{E}$ near Somali and carry abundant water vapor into the $\mathrm{NH}$ enhance the surface wind convergence and the rainfall in South China. Therefore, we can conclude that these two enhanced anticyclones are attributable to the eastward movements or extensions of the $\mathrm{MH}$ and $\mathrm{AH}$ and affect the rainfall in South China by influencing the wind fields and CEFs.

As proposed in previous studies, the ENSO is an important factor affecting the interannual variations of the $\mathrm{MH}$, and the $\mathrm{MH}$ tends to be more intense during an El Niño event [45]. Furthermore, Xue et al. [35] suggested that the ENSO is the factor that triggers $\mathrm{AH}$ anomalies, whereas the $\mathrm{AAO}$ not ENSO is the factor that triggers anomalous intensities in the $\mathrm{MH}$. However, these results do not indicate the external forcing of the eastward movements or extensions of the $\mathrm{MH}$ and $\mathrm{AH}$ or the possible underlying physical mechanisms. Here, we further investigate the dynamics of the possible impacts of SST anomalies on the eastward movements or extensions of $\mathrm{MH}$ and $\mathrm{AH}$. The correlation coefficients of the IEAH and IEMH in the prerainy season with the global SST anomalies from the preceding winter are shown in Figure 11. Significant positive correlation coefficients dominate the central and eastern equatorial Pacific, northwestern Pacific, and middle-high latitudes of the South Indian Ocean, whereas negative correlation coefficients appear over the middle of the northern Pacific (Figure 11(a)). The results of the correlation analysis present a typical ENSO pattern. The correlation relationship between the IEAH and SST anomalies over the central and eastern equatorial Pacific in the prerainy season is even more significant (image omitted). Therefore, we infer that the ENSO exerts a continuous, significant influence on the eastward movement or extension of the AH. Correlations of IEMH in the prerainy season with the global SST anomalies from the preceding winter are shown in Figure 11(b) and exhibit SST anomaly patterns that differ from those in Figure 11(a). In the tropical Pacific, no positive or negative correlation coefficient passes the 95\% confidence level ( $t$-test). In the South Indian Ocean, significant positive correlation coefficients are found in the southwest and negative correlation coefficients are found in the northeast. This pattern of SST anomalies is similar to that of the positive subtropical Indian Ocean dipole (SIOD) 


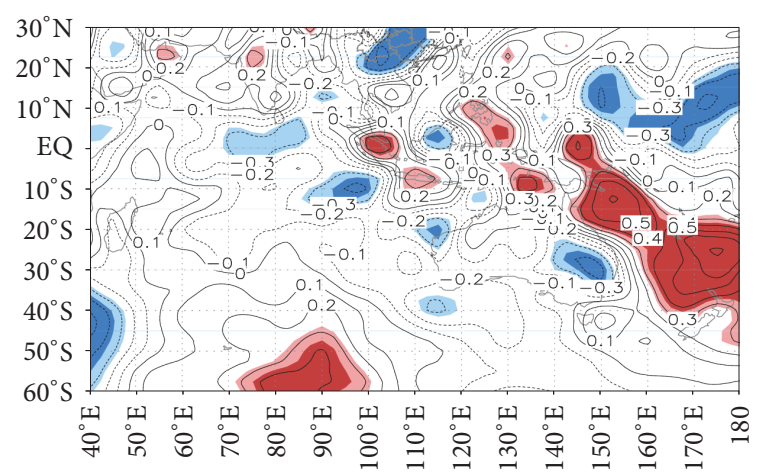

(a)

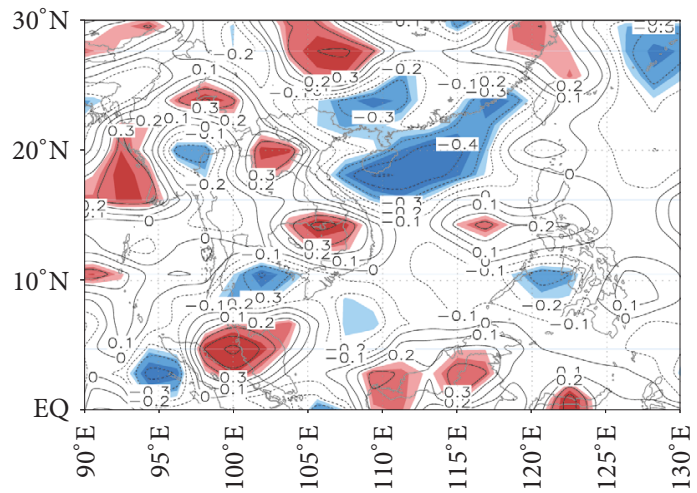

(c)

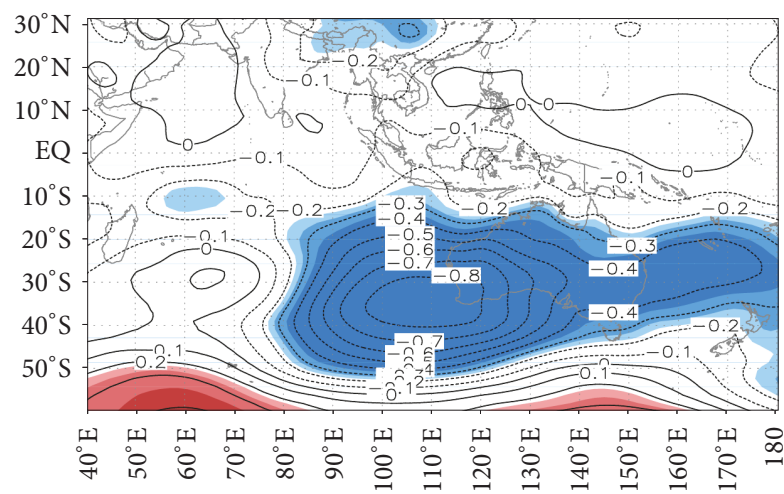

(e)

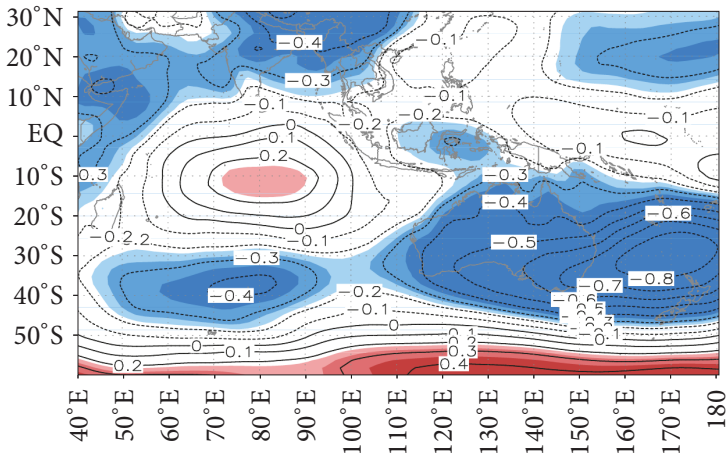

(b)

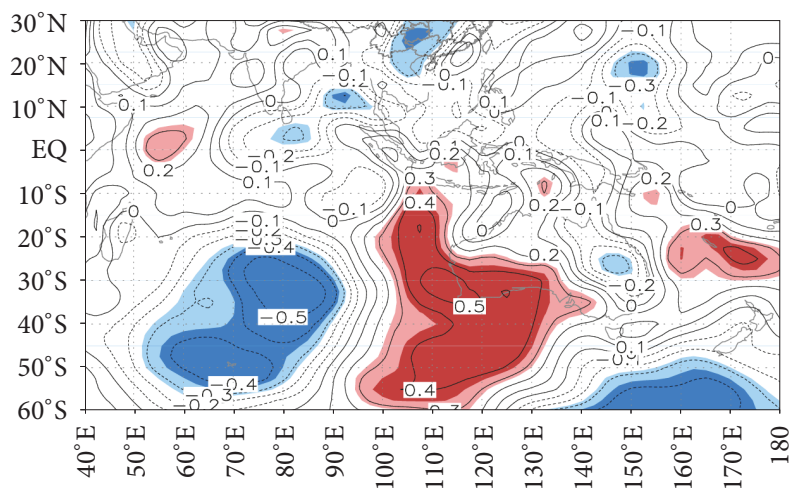

(d)

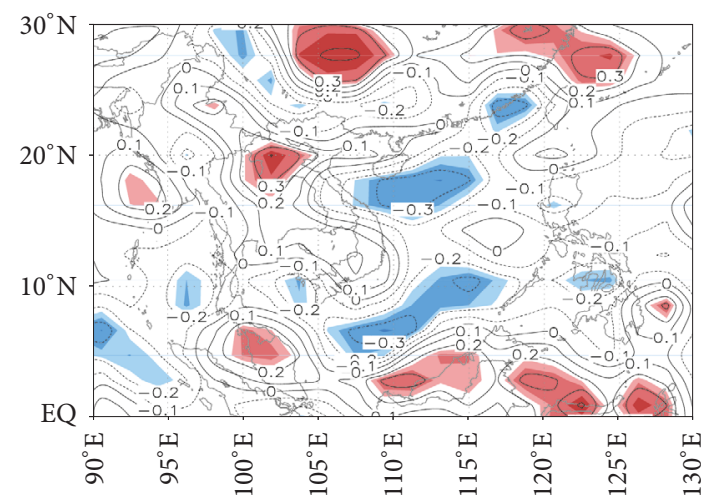

(f)

FIGURE 10: Correlation between the $850 \mathrm{hPa}$ meridional wind, surface wind divergence, and velocity potential with the (a)-(c) IEAH and the (d)-(f) IEMH. Significant values exceeding the 90\%, 95\%, and 99\% confidence levels ( $t$-test) are shaded.

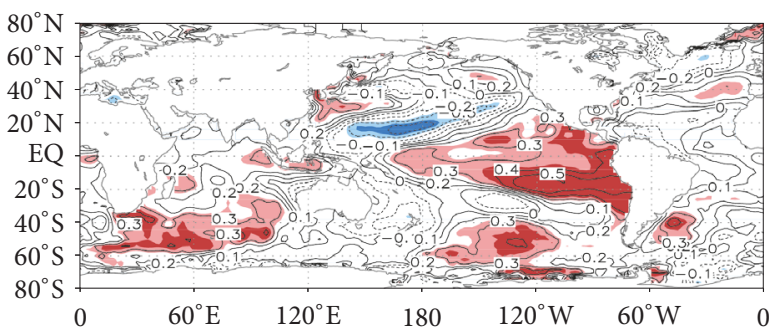

(a)

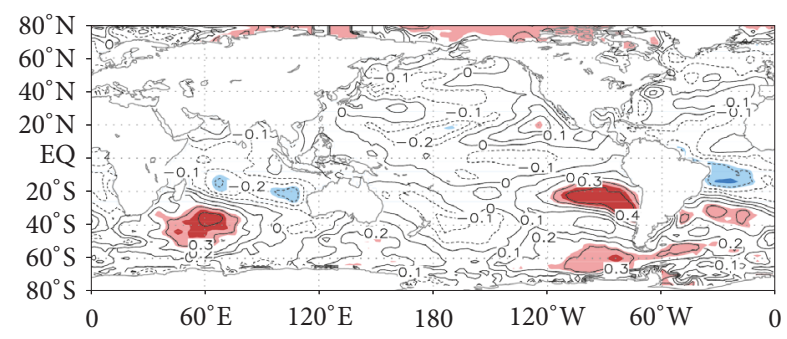

(b)

FIGURE 11: Correlation analyses of the IEAH (a) and IEMH (b) with the global SST anomalies from the preceding winter. Significant values exceeding the $90 \%, 95 \%$, and $99 \%$ confidence levels ( $t$-test) are shaded. 
phase, which displays an opposite distribution of variability between the northeast $\left(10^{\circ}-20^{\circ} \mathrm{S}, 65^{\circ}-95^{\circ} \mathrm{E}\right)$ and the southwest $\left(35^{\circ}-55^{\circ} \mathrm{S}, 45^{\circ}-75^{\circ} \mathrm{E}\right)$ regions of the Indian Ocean. Thus, the external forcing of the eastward movement or extension of the $\mathrm{MH}$ is the local air-sea interactions in the South Indian Ocean, and not the ENSO.

\section{Summary and Discussion}

In this study, we investigated the features of the PSCPRS and the atmospheric circulation in the $\mathrm{SH}$ expected to influence the PSCPRS significantly. We have specifically addressed the following three questions. (1) Is there a prominent variation in the period of the PSCPRS? The Morlet wavelet method revealed a significant interannual variability in the PSCPRS, including a significant QBO, which exhibits significant monsoonal precipitation characteristics. The next question is as follows: (2) Are there possible links between the atmospheric circulation in the $\mathrm{SH}$ and the variations in the PSCPRS? The results of the SVD and composite analyses showed that the anomalous patterns of the $\mathrm{MH}$ and $\mathrm{AH}$ were the most significant factors affecting the PSCPRS. Finally, (3) what is the possible impact of the anomalous patterns of the $\mathrm{MH}$ and $\mathrm{AH}$ on the PSCPRS, and what are the possible underlying physical mechanisms? The eastward movements or extensions of the $\mathrm{MH}$ and $\mathrm{AH}$, which have quasi-baroclinic $\mathrm{GH}$ structures in the lower and middle troposphere, and their impacts on the PSCPRS anomalies are further studied using the definitions of the IEMH and IEAH. The IEMH and IEAH exhibit notable significant positive correlations with the PSCPRS. When either the IEMH or IEAH is stronger (weaker), there is more (less) rainfall during the prerainy season in South China. Additionally, the results of the composite analyses of the atmospheric circulation reveal the possible physical mechanisms through which atmospheric circulation anomalies in the SH impact the PSCPRS. The results indicate that the eastward movements or extensions of the $\mathrm{MH}$ and AH influence on PSCPRS anomalies in different ways. When the $\mathrm{AH}$ moves or extends eastward, the southerly winds along the edge of the anticyclone are actively intensified and can then carry abundant water vapors from the South Pacific into the $\mathrm{NH}$ by exciting the CEFs near $140^{\circ}-150^{\circ} \mathrm{E}, 120^{\circ}-130^{\circ} \mathrm{E}$, and $100^{\circ}-110^{\circ} \mathrm{E}$. Meanwhile, stronger horizontal dynamic convergence over the South China can trigger the regional ascending motion. As a result, precipitation increases in South China. However, the eastward movements or extensions of the $\mathrm{MH}$ could enhance the southerly winds along the edge of the anticyclone, which can then cross the equator at $50^{\circ}-60^{\circ} \mathrm{E}$ near Somalia, carrying abundant water vapor into the $\mathrm{NH}$ and following strong dynamical convergence, thus, enhancing the rainfall in South China.

We also discussed the external forcing of the anomalous atmospheric circulations. The correlation analyses indicate that the SST anomalies over crucial oceanic areas are the key factors forcing the anomalous atmospheric circulations in the $\mathrm{SH}$. As an external cause of atmospheric circulation, the ENSO can affect the anomalous pattern of the AH continuously. However, the ENSO is not the cause for the anomalous pattern of the $\mathrm{MH}$. Instead, the positive phases of SIOD events contribute to the anomalous pattern of the $\mathrm{MH}$. Studies by Yang and Ding $[46,47]$ indicate that the SIOD can enhance (weaken) the $\mathrm{MH}$ and result in enhanced (weakened) Somali CEFs, which is associated with increased (decreased) total northward water vapor transport to China. Moreover, previous studies indicated that the atmosphereocean covariability associated with the SIOD linked to the subtropical anticyclone, which is also associated with the AAO. During the mature phase of the positive SIOD, the corresponding anticyclone over the South Indian Ocean is strengthened. This suggests atmosphere-to-ocean forcing. A stronger anticyclone, which is characterized by the intensification of the $\mathrm{MH}$, leads to increased southeasterlies to the west of Australia, which are linked to increased evaporation and stronger upper-ocean mixing and lower the SST in this region. In the southwest, over the central mid-latitudes, the westerlies are weaker, implying reduced evaporation and upper-ocean mixing, which contribute to a warmer ocean in the southwestern Indian Ocean. The latter result means that the $\mathrm{MH}$ is one forcing factor for the SIOD, as mentioned in previous studies [48-53]. After the peak of the SIOD, the high pressure is weakened and moves eastward [54]. Thus, the eastward movement of the $\mathrm{MH}$ enhances the rainfall in South China. The processes that are active at the boundary between the atmosphere and ocean were expected to shed some light on the coupled mechanisms. However, some of the physical processes remain unclear. Therefore, we suggest that more attention should be paid to the interactions of the atmosphere-ocean-ice system, especially in the $\mathrm{SH}$ middle latitudes.

\section{Conflicts of Interest}

The authors declare that they have no conflicts of interest.

\section{Acknowledgments}

This study was supported by the National Natural Science Foundation of China (Grant nos. 41306007, 41576029, 40975044, and 41106004), the National Science \& Technology Supporting Program under Grant no. 2009BAC51B04, and the National program on Global Change and Air-Sea Interaction under Grant no. GASI-IPOVAI-03. The authors would like to thank Dr. Li Yan (Research Assistant of National Marine Data \& Information Service) for her continuous support.

\section{References}

[1] B. Meneghini, I. Simmonds, and I. N. Smith, "Association between Australian rainfall and the Southern Annular Mode," International Journal of Climatology, vol. 27, no. 1, pp. 109-121, 2007.

[2] B. A. Raut, C. Jakob, and M. J. Reeder, "Rainfall changes over Southwestern Australia and their relationship to the southern annular mode and ENSO," Journal of Climate, vol. 27, no. 15, pp. 5801-5814, 2014.

[3] N. P. Gillett, T. D. Kell, and P. D. Jones, "Regional climate impacts of the Southern Annular Mode," Geophysical Research Letters, vol. 33, no. 23, Article ID L23704, 2006. 
[4] G. Silvestri and C. Vera, "Nonstationary impacts of the southern annular mode on Southern Hemisphere climate," Journal of Climate, vol. 22, no. 22, pp. 6142-6148, 2009.

[5] L. M. V. Carvalho, C. Jones, and T. Ambrizzi, "Opposite phases of the Antarctic oscillation and relationships with intraseasonal to interannual activity in the tropics during the austral summer," Journal of Climate, vol. 18, no. 5, pp. 702-718, 2005.

[6] K. Fan and H.-J. Wang, "Simulation of the AAO anomaly and its influence on the northern hemispheric circulation in boreal winter and spring," Chinese Journal of Geophysics, vol. 50, no. 2, pp. 397-403, 2007 (Chinese).

[7] M. R. Ramesh Kumar, R. Krishnan, S. Sankar et al., "Increasing trend of break-monsoon conditions over india-role of oceanatmosphere processes in the indian ocean," IEEE Geoscience and Remote Sensing Letters, vol. 6, no. 2, pp. 332-336, 2009.

[8] M. J. Rodwell and B. J. Hoskins, "Subtropical anticyclones and summer monsoons," Journal of Climate, vol. 14, no. 15, pp. 31923211, 2001.

[9] Z. Wu, J. Li, B. Wang, and X. Liu, "Can the Southern Hemisphere annular mode affect China winter monsoon?" Journal of Geophysical Research Atmospheres, vol. 114, no. 11, Article ID D11107, 2009.

[10] Z. Wu, J. Dou, and H. Lin, "Potential influence of the NovemberDecember Southern Hemisphere annular mode on the East Asian winter precipitation: a new mechanism," Climate Dynamics, vol. 44, no. 5-6, pp. 1215-1226, 2015.

[11] T. Liu, J. Li, and F. Zheng, "Influence of the boreal autumn southern annular mode on winter precipitation over land in the Northern Hemisphere," Journal of Climate, vol. 28, no. 22, pp. 8825-8839, 2015.

[12] G. E. Silvestri and C. S. Vera, "Antarctic oscillation signal on precipitation anomalies over Southeastern South America," Geophysical Research Letters, vol. 30, no. 21, pp. 1-4, 2003.

[13] C. J. C. Reason and M. Rouault, "Links between the Antarctic Oscillation and winter rainfall over western South Africa," Geophysical Research Letters, vol. 32, no. 7, pp. 1-4, 2005.

[14] S. Nan and J. Li, "The relationship between the summer precipitation in the yangtze river valley and the boreal spring southern hemisphere annular mode," Geophysical Research Letters, vol. 8, no. 24, pp. 171-175, 2003.

[15] H. Gao, F. Xue, and H. J. Wang, "Influence of interannual variability of Antarctic Oscillation on Mei-yu along the Yangtze and Huaihe River Valley and its importance to prediction," Chinese Science Bulletin, vol. 48, no. 25, pp. 61-67, 2003 (Chinese).

[16] K. Fan, "Atmospheric circulation anomalies in the southern hemisphere and summer rainfall over yangtze river valley," Chinese Journal of Geophysics, vol. 49, no. 3, pp. 672-679, 2006 (Chinese).

[17] J. Sun, H. Wang, and W. Yuan, "A possible mechanism for the co-variability of the boreal spring Antarctic Oscillation and the Yangtze River valley summer rainfall," International Journal of Climatology, vol. 29, no. 9, pp. 1276-1284, 2009.

[18] F. Zheng and J. P. Li, "Impact of preceeding boreal winter southernhemisphere annular mode on spring precipitation over south China and related mechanism," Chinese Journal of Geophysics-Chinese Edition, vol. 55, no. 11, pp. 3542-3557, 2012.

[19] F. Xue, "Influence of the southern circulation on EASM," Climatic and Environmental Research, vol. 10, no. 3, pp. 401-408, 2005 (Chinese).

[20] R. A. Tomas and P. J. Webster, "Horizontal and vertical structure of cross-equatorial wave propagation," Journal of the Atmospheric Sciences, vol. 51, no. 11, pp. 1417-1430, 1994.
[21] S. Nan, J. Li, X. Yuan, and P. Zhao, "Boreal spring Southern Hemisphere Annular Mode, Indian Ocean sea surface temperature, and East Asian summer monsoon," Journal of Geophysical Research Atmospheres, vol. 114, no. 2, Article ID D02103, 2009.

[22] D. Manatsa, Y. Morioka, S. K. Behera, C. H. Matarira, and T. Yamagata, "Impact of Mascarene High variability on the East African "short rains"," Climate Dynamics, vol. 42, no. 5-6, pp. 1259-1274, 2014.

[23] S. Ohishi, S. Sugimoto, and K. Hanawa, "Zonal movement of the Mascarene High in austral summer," Climate Dynamics, vol. 45, no. 7-8, pp. 1739-1745, 2014.

[24] K.-H. Wyrwoll, J. M. Hopwood, and G. Chen, "Orbital timescale circulation controls of the Australian summer monsoon: a possible role for mid-latitude Southern Hemisphere forcing?" Quaternary Science Reviews, vol. 35, pp. 23-28, 2012.

[25] S. Rehman, K. Khan, and A. Ahmed, "Association between the dynamics of indian ocean subtropical high and winter time precipitation and stream flow: acase study over acheron river catchment, victoria," British Journal of Applied Science \& Technology, vol. 12, no. 3, pp. 1-9, 2016.

[26] S. Rehman, "Influence of indian ocean highpressure on streamflow variability oversouthwestern australia," Annals of Geophysics, vol. 57, no. 2, pp. 1-25, 2014.

[27] S. Hameed, M. J. Iqbal, Saqib-Ur-Rehman, and D. Collins, "Impact of the Indian Ocean high pressure system on winter precipitation over western and southwestern Australia," Australian Meteorological and Oceanographic Journal, vol. 61, no. 3, pp. 159-170, 2011.

[28] J. H. He, J. Li, and P. Li, "Numerical experiment with processes for effect of australian cold air activity on EASM," Acta Meteorologica Sinica, vol. 49, no. 2, pp. 162-169, 1991 (Chinese).

[29] M. J. Rodwell, "Breaks in the Asian monsoon: the influence of Southern Hemisphere weather systems," Journal of the Atmospheric Sciences, vol. 54, no. 22, pp. 2597-2611, 1997.

[30] F. Xue, D. Jian, X. Lang, and H. Wang, "Influence of the mascarene high and Australian high on the summer monsoon in East Asia: ensemble simulation," Advances in Atmospheric Sciences, vol. 20, no. 5, pp. 799-809, 2003.

[31] F. Xue, H. Wang, and J. He, "Interannual variability of Mascarene high and Australian high and their influences on East Asian summer monsoon," Journal of the Meteorological Society of Japan, vol. 82, no. 4, pp. 1173-1186, 2004.

[32] S. Y. Tao, S. Y. Hu, and C. Y. Kuo, "The characteristics of the zonal and meridional circulation over tropical and subtropical regions in Eastern Asia in summer," Acta Meteorological Sinica, vol. 32, no. 2, pp. 91-103, 1962 (Chinese).

[33] J. Z. Wang and M. C. Li, "Cross-equator flow from australia and monsoon over China," Chinese Journal of Atmospheric Sciences, vol. 6, no. 1, pp. 1-10, 1982 (Chinese).

[34] D. G. Teng, X. F. Liu, Z. X. Zhang et al., "Interannual variation of Australian high and its effect on Asia-Australia monsoon circulation system in summer," Journal of Nanjing Institute of Meteorology, vol. 28, no. 1, pp. 86-92, 2005 (Chinese).

[35] F. Xue, H. Wang, and J. He, "Interannual variability of Mascarene high and Australian high and their influences on summer rainfall over East Asia," Chinese Science Bulletin, vol. 48, no. 5, pp. 492-497, 2003.

[36] F. Xue and J. He, "Influence of the Southern Hemispheric circulation on east-west oscillation of the western Pacific subtropical high," Chinese Science Bulletin, vol. 50, no. 14, pp. 1532-1536, 2005 (Chinese). 
[37] X. Q. Yang and S. S. Huang, "The influence of intensity change of mascarene high on the general circulation of atmosphere-a numerical experiment," Scientia Meteorologica Sinica, vol. 9, no. 2, pp. 125-138, 1989 (Chinese).

[38] N. Q. Tao and Z. B. Sun, "Influence of Mascarene High on Meiyu precipitation in Changjiang-Huaihe basin," Journal of Nanjing Institute of Meteorology, vol. 30, no. 6, pp. 786-791, 2007 (Chinese).

[39] N. Shi and Q. G. Zhu, "The climatic features of the Australia high and the Mascarene High in southern hemisphere and their influence on the summer precipitation on Eastern China," Scientia Meteorologica Sinica, vol. 15, no. 2, pp. 20-27, 1995 (Chinese).

[40] H. Ma, Z. H. Chen, W. S. Mao et al., "Analysis of precipitation in the annually first rainy period and general circulation in the south of China," Journal of Tropical Meteorology, vol. 25, no. 1, pp. 89-96, 2009 (Chinese).

[41] S. Matsumura, S. Sugimoto, and T. Sato, "Recent intensification of the western pacific subtropical high associated with the east Asian summer monsoon," Journal of Climate, vol. 28, no. 7, pp. 2873-2883, 2015.

[42] C. Wu, A. Wang, W. Lin et al., "The establishment of the South China sea summer monsoon in 1998: the northward jump of South Asia anticyclone and its effect on the onset of South China sea summer monsoon," Journal of Meteorological Research, supplement 1, pp. 35-45, 2003.

[43] J. Mao, J. C. L. Chan, and G. Wu, "Relationship between the onset of the South China Sea summer monsoon and the structure of the Asian subtropical anticyclone," Journal of the Meteorological Society of Japan, vol. 82, no. 3, pp. 845-859, 2004.

[44] N. Shi, D. P. Shi, and M. L. Yan, "The effects of cross-equatorial current on South China Sea monsoon onset and drought/flood in East China," Journal of Tropical Meteorology, vol. 17, no. 4, pp. 405-414, 2001 (Chinese).

[45] J. Cui and X. Q. Yang, "The variation of Mascarene High and its relationship with ENSO," Scientia Meteorologica Sinica, vol. 25, no. 5, pp. 441-449, 2005 (Chinese).

[46] M. Z. Yang and Y. H. Ding, "Diagnostic study of the variation of Indian Ocean sea surface temperature and its impact on Indian summer monsoon rainfalls," Acta Oceanologica Sinica, vol. 28, no. 4, pp. 9-16, 2006 (Chinese).

[47] M. Z. Yang and Y. H. Ding, "A study of the impact of South Indian Ocean dipole on the summer rainfall in China," Chinese Journal of Atmospheric Sciences, vol. 31, no. 4, pp. 685-694, 2007 (Chinese).

[48] S. A. Venegas, L. A. Mysak, and D. N. Straub, "An interdecadal climate cycle in the South Atlantic and its links to other ocean basins," Journal of Geophysical Research: Oceans, vol. 103, no. 11, pp. 24723-24736, 1998.

[49] L. Goddard and N. E. Graham, "Importance of the Indian Ocean for simulating rainfall anomalies over Eastern and Southern Africa," Journal of Geophysical Research Atmospheres, vol. 104, no. 16, pp. 19099-19116, 1999.

[50] S. K. Beherea and T. Yamagata, "Subtropical SST dipole events in the southern Indian Ocean," Geophysical Research Letters, vol. 28, no. 2, pp. 327-330, 2001.

[51] C. J. C. Reason, "Subtropical Indian Ocean SST dipole events and southern African rainfall," Geophysical Research Letters, vol. 28, no. 11, pp. 2225-2227, 2001.

[52] C. J. C. Reason, "Sensitivity of the southern African circulation to dipole sea-surface temperature patterns in the South Indian
Ocean," International Journal of Climatology, vol. 22, no. 4, pp. 377-393, 2002.

[53] J. Feng, D. Hu, and L. Yu, "How does the Indian Ocean subtropical dipole trigger the tropical Indian Ocean dipole via the Mascarene high?" Acta Oceanologica Sinica, vol. 33, no. 1, pp. 64-76, 2014.

[54] J. C. Hermes and C. J. C. Reason, "Ocean model diagnosis of interannual coevolving SST variability in the South Indian and South Atlantic Oceans," Journal of Climate, vol. 18, no. 15, pp. 2864-2882, 2005. 

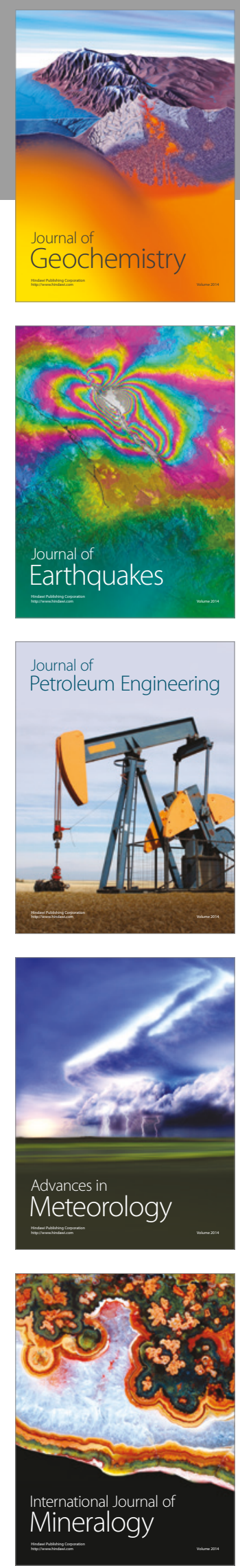
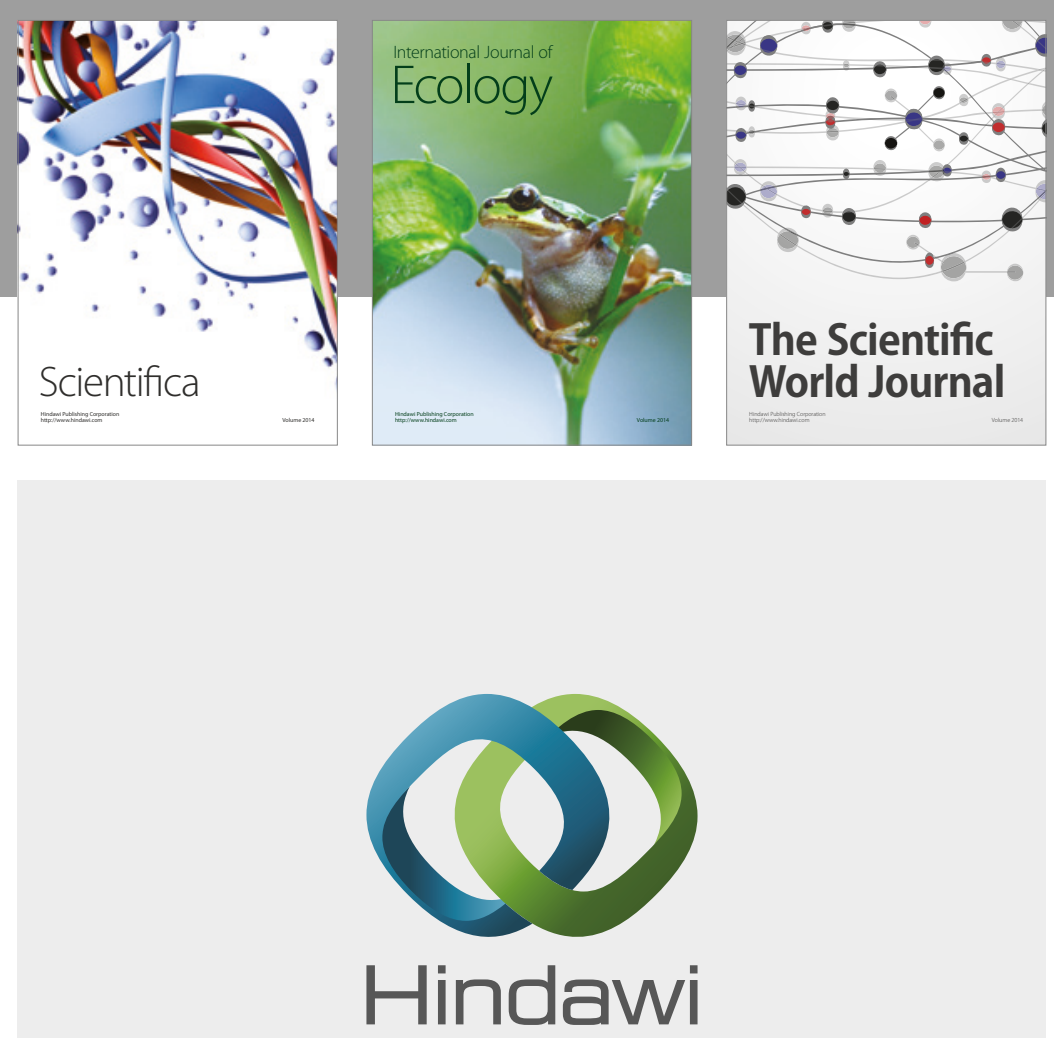

Submit your manuscripts at

https://www.hindawi.com
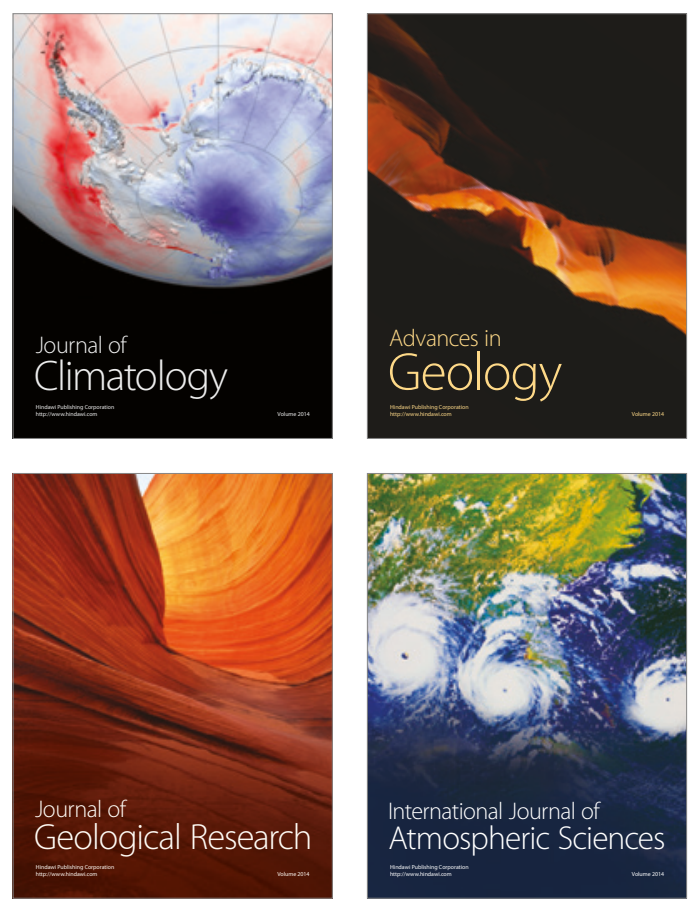

The Scientific

World Journal
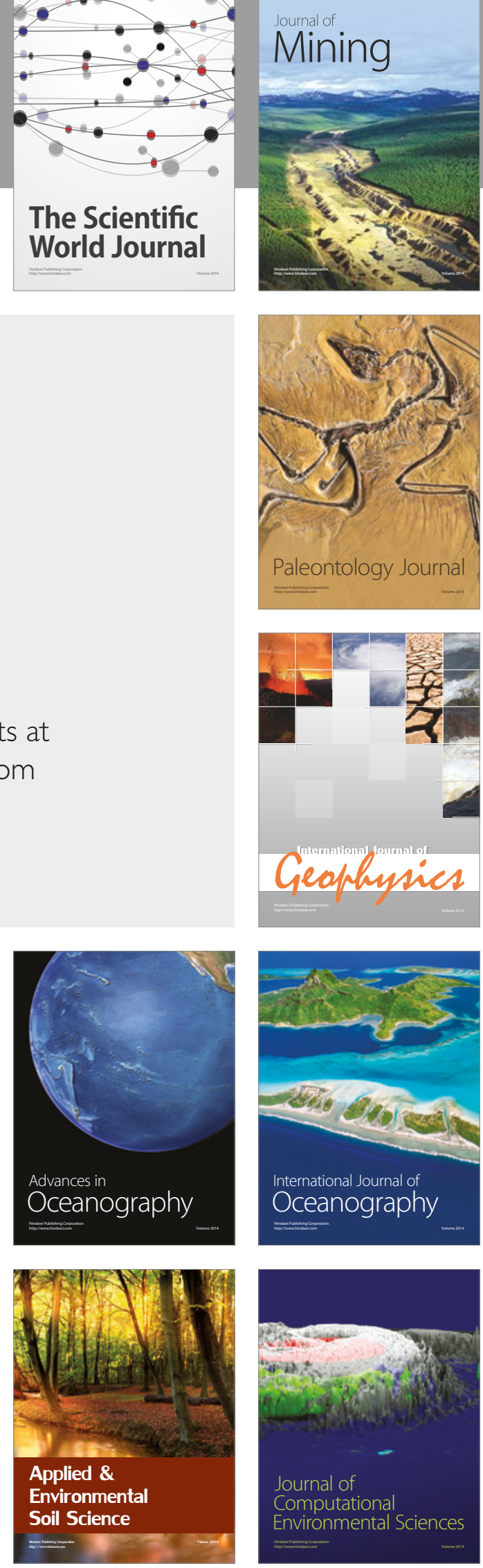